\title{
Community Pharmacy's Role in Promoting Healthy Behaviours
}

\author{
Andrew W Joyce, V Bruce Sunderland, Suzanne Burrows, Alexandra McManus, \\ Peter Howat, Bruce Maycock
}

\begin{abstract}
Many have commented on the potential of community pharmacy as a health promotion setting, due to accessibility, high level of use, and the respect afforded to pharmacists. Community pharmacy could be a setting through which to address risk and protective health behaviours relevant to Australia's National Health Priority Areas. However, apart from some studies on smoking cessation, there is scant evidence on its involvement in other healthy behaviours. This paper discusses how to increase research and interventions on healthy behaviours in community pharmacy. This includes placing community pharmacy's role within a broader health promotion context, expanding community expectations of pharmacists, and addressing barriers to performing a health promotion role.
\end{abstract}

J Pharm Pract Res 2007; 37: 42-4.

\section{INTRODUCTION}

Community pharmacies can be accessible sites for health promotion. ${ }^{1-3}$ Pharmacies are recognised as the most accessible healthcare service in the community with over $90 \%$ of the population visiting during one year. ${ }^{1,4}$ Community pharmacies are patronised by both healthy and sick people, thus having access to a large proportion of the population - before major illness or disease is evident. ${ }^{5}$

Community pharmacists may be able to capture populations who are not motivated to use other health services. ${ }^{6}$ Therefore, placing community pharmacy as a setting through which to address key health behaviours, e.g. smoking cessation, healthy nutrition, alcohol consumption, physical activity. ${ }^{7}$ General practitioners have been provided with a support guide for addressing these four health behaviour issues. ${ }^{8}$ This is based on the contribution of these behaviours towards the burden of disease and the evidence base for general practitioners' targeting these risk and protective factors. ${ }^{8}$

A literature search was conducted to assess the evidence for community pharmacy involvement in health promotion activities relevant to the four health behaviours. The search covered the period 1985 to February 2006 using Medline, Cochrane Database of Systematic Reviews, International Pharmaceutical Abstracts, and Australasian Medical Index. Search strategies included the terms: 'pharmacy or pharmacist', 'pharmaceutical care', 'diet', 'weight loss', 'weight management', 'nutrition', 'smoking', 'alcohol', 'health promotion', 'education', 'intervention', 'prevention', 'screening or detection', and 'physical activity'. Articles were selected if they addressed smoking, nutrition, physical activity, or alcohol consumption. Surveys of community pharmacy involvement in

Andrew W Joyce, ${ }^{1,2}$ BA(Hons), DipEd, DPsych, Lecturer, V Bruce Sunderland, ${ }^{2} \mathrm{PhD}$, Professor, Suzanne Burrows, ${ }^{2}$ DipPharm, FPS, Lecturer, Alexandra McManus, ${ }^{1} \mathrm{PhD}$, Senior Research Fellow, Peter Howat, ${ }^{1,3,4} \mathrm{PhD}$, Professor, Bruce Maycock, ${ }^{1,4} \mathrm{PhD}$, Associate Professor, ${ }^{1}$ WA Centre for Health Promotion Research, ${ }^{2}$ School of Pharmacy, ${ }^{3}$ Centre for Behavioural Research in Cancer Control, ${ }^{4}$ National Drug Research Institute, Curtin University of Technology, Perth, Western Australia

Address for correspondence: Dr Andrew Joyce, WA Centre for Health Promotion Research, Curtin University of Technology, Perth WA 6845, Australia E-mail: A.Joyce@curtin.edu.au health promotion activities and consumer experience of these services were also selected. We also examined community pharmacy-led programs for these four health behaviours.

The research base for community pharmacy involvement in these areas is not well developed. Maybe because research and programs need to place the role of community pharmacy within a broader health promotion context and target barriers to its involvement in health promotion. Research and program development is needed to change consumer expectations and their use of community pharmacy services. The aim of this paper is to discuss how to increase research and interventions on healthy behaviours in community pharmacy.

\section{PROGRAMS}

\section{Smoking Cessation}

Two randomised controlled trials have shown promising results for providing smoking cessation advice in community pharmacies. ${ }^{9,10}$ In one study, pharmacists from the intervention group were trained in the Transtheoretical Model focusing on the preparation, action, maintenance and relapse stages. ${ }^{9}$ The intervention group $(\mathrm{n}=224)$ was more likely to have abstained from smoking at each of the follow-up points with the last at 9 months when $12 \%$ of the intervention group and $7.4 \%$ of controls ( $n=268)$ had abstained (difference was not statistically significant). The second study demonstrated significant differences in smoking cessation rates between those receiving pharmacy advice $(n=265)$ compared to controls $(n=219) .{ }^{10}$ In the intervention group, pharmacists provided a 10 to 30 minute consultation in which personal and medical data were recorded and motivations and goals discussed and recorded. At each of the monthly follow-ups the intervention group displayed higher abstinence rates, with a 12-month endpoint of $14.3 \%$ for the intervention group and $2.7 \%$ for controls. This was a significant difference although the abstinence rate for the intervention group of $14.3 \%$ was similar to that demonstrated by Sinclair et al. (12\%). ${ }^{11}$

\section{Alcohol Consumption}

The Pharmacy Guild of Australia conducted a nationwide campaign on safe alcohol consumption in $2004 .{ }^{12}$ On the inside cover of a pharmacy prescription folder there was a drink chart depicting standard drink sizes and on the outside a safe drinking message and general guidelines on safe drinking. Pharmacists could advise on drug and alcohol interactions as well as providing advice on general consumption issues. Evaluation revealed that both clients and pharmacists felt the folder increased the ease and likelihood of conversations relevant to alcohol consumption. ${ }^{12}$

\section{Healthy Nutrition}

As of May 2005 , more than $60 \%$ of Australian community pharmacies were offering weight management services through the 'Lifeweight' program. ${ }^{13}$ This coincided with the change in classification of orlistat in May 2004 to a pharmacist-only product. ${ }^{13}$ However, there are few published cognitive-based weight loss programs and there are no specific studies examining community pharmacy interventions aimed at healthy nutrition. 
A US study investigated the suitability of pharmacy as a weight loss program setting. ${ }^{14}$ Participants were randomly allocated to either a 12 -week meal replacement program or a 12 -week reduced-calorie diet program. For the 55 participants who completed the 22-week study, there was significant weight loss in both groups and this was maintained at the 10-week followup. In respect of biomedical markers, there was a significant decrease in blood pressure across the 22 weeks.

\section{Physical Activity}

Participation in physical activity is one of the key determinants in preventing ill health and disability. Very few studies have investigated whether advice from community pharmacists can increase consumers' physical activity levels. A screening study for cardiovascular risk factors conducted in rural New South Wales found that among those who received pharmacist advice on physical activity, there was a decrease in the number selfreporting inadequate physical activity. ${ }^{2}$

\section{INVOLVEMENT AND PERCEPTIONS}

A number of studies have examined the frequency with which pharmacies provide extended services other than dispensing. In British Columbia, 581 pharmacies were surveyed about the frequency with which they provide health education and disease prevention services and advice. ${ }^{15}$ Participation in health education activities was low, with only a third regularly participating in activities such as obtaining data on smoking and participating in community health events or speaking to community groups. A similar study in Quebec demonstrated low participation rates in activities such as cardiovascular disease screening, smoking cessation and initiating discussions about health, with no more than a third of pharmacists regularly undertaking such work. ${ }^{16}$ In the UK, a large study found higher participation in health promotion (posters, counselling), with over $80 \%$ of the sample of 731 community pharmacies undertaking this type of activity. ${ }^{17}$

While there are mixed findings on pharmacy involvement in health promotion, community perceptions support pharmacies as a health promotion site. ${ }^{18}$ Australian researchers surveyed rural people about which source of health prevention information was most important and the doctor and pharmacist were the two standout responses, followed by media sources such as newspapers, magazines and health pamphlets. ${ }^{19} \mathrm{~A}$ pharmacy health promotion project conducted in the UK found that many customers had not intended to visit the pharmacy for advice but once provided, felt it had been of benefit. ${ }^{20}$

Research has also examined consumer and pharmacist experience on specific health topics. A study investigated how receptive smokers would be to advice and counselling from a pharmacist. ${ }^{21}$ They interviewed 103 participants who had recently bought nicotine replacement therapy. Five participants had been asked by a pharmacist whether they smoked and only two had received advice on their smoking from a pharmacist. The participants felt that it was appropriate for pharmacists to advise about smoking and the overwhelming majority thought that advice from a pharmacist on smoking cessation would be useful. Around half of the participants were willing to pay $\$ 10$ for a counselling service and two-thirds would use a counselling service if it was free. Comparable research has also found low counselling rates from pharmacy services in relation to smoking cessation. In a study of 609 pharmacists in North Carolina and Texas $(41 \%$ response rate) $7.5 \%$ inquired about a customer's smoking status. ${ }^{22}$ It appears that there is potential for an increase in opportunistic health promotion counselling in community pharmacy. However, interventions from US studies may not be translated to Australian interventions owing to markedly different community pharmacy structures.

\section{HEALTH PROMOTION}

Health promotion in Australia has produced a number of successes, most noticeably reduction in smoking rates, decreasing road fatalities, decreasing rates of cardiovascular disease and reducing rates of skin cancer. ${ }^{23}$ The strength lies in a multidisciplinary approach incorporating organisational, economic, policy, and educational interventions. ${ }^{24}$ Educational interventions have limited ability to produce behavioural change but can support and augment other interventions..$^{25}$ Thus, while increasing education may not directly alter behaviour it may improve attitude and knowledge, and lead to increased support for economic, organisational and policy interventions that would be more effective in driving change.

Public health, and within its domain, health promotion, has adopted a social model of health which emphasises responding to the broader environmental determinants of health that support and promote wellbeing. ${ }^{26}$ According to Wass, this sets wide parameters in which health promotion can operate and affords the opportunity to address the root causes of ill health. ${ }^{26}$ Growing evidence demonstrates the importance of economic and social conditions in influencing states of health and illness. ${ }^{27}$ This approach is well captured by the Ottawa Charter and Jakarta Declaration on health promotion which emphasises partnerships and creating supportive environments for health. ${ }^{28,29}$

This emphasis on environmental determinants ofhealth does not preclude individual and behavioural approaches - rather, such approaches need to be supported by an appropriate economic and social infrastructure that supports positive health. Community pharmacies can take an active role at an individual and community level to support the health of their communities, and thus move their service in a health promotion direction consistent with the Ottawa Charter ${ }^{28}$ Community pharmacists have been encouraged to provide advice and support community programs on physical activity and a review of smoking cessation interventions concluded that pharmacies have an important and obligated role in providing at least brief cessation advice. ${ }^{30-32}$ This health promotion service is one aspect of the broad public health role of community pharmacy. ${ }^{33}$

Given that healthy behaviour change requires multiple strategies, it is also worth considering the evaluation benchmarks for community pharmacy health promotion programs. ${ }^{24}$ While smoking cessation programs conducted in community pharmacy have been evaluated against behavioural change, this may not be appropriate for all health behaviours. While a broadly based program, where community pharmacy was part of an overall strategy, may desire to achieve behavioural change at a public health level, assessing interventions based only in community pharmacy may need to consider impact measures, such as changes in attitude, knowledge or behavioural intention, as precursors of healthy behaviour change. ${ }^{34}$

\section{BARRIERS}

One of the keybarriers to pharmacies offering health promotion services is remuneration. ${ }^{1,5,10,16,35-37}$ Incentive payments are one of the key criteria determining pharmacies' effectiveness in providing smoking cessation services. ${ }^{38}$ A project piloted a model of health promotion in community pharmacy in four rural areas and this included a small grants component. ${ }^{39}$ As well as compensating for the in-store health education provided by pharmacists and pharmacy assistants, the pharmacies were able to organise or support community activities (e.g. mental health workshops, exercise groups, infant health groups, cardiovascular disease and diabetes screening, breast cancer awareness, falls prevention talks, supermarket tours for diabetics, school-based health promotion). This addressed both the remuneration component and offered valuable services to 
rural populations. These communities use fewer health services, suffer from poorer health than urban populations and have less access to health promotion information. . $^{1940-44}$

Another barrier is the level of skill and confidence of pharmacists and pharmacy assistants. ${ }^{15,16,22,35}$ Pharmacists have been trained in behaviour change principles for delivering smoking cessation advice. ${ }^{37}$ While training in behaviour change and educational principles is important, this reflects only one aspect of a health promotion approach. While some areas are beyond the scope of community pharmacy, they could take a lead role within a community, particularly in rural areas, in relation to health promotion activities which accord with health promotion and public health movements towards community partnerships and involvement. ${ }^{26,28,29}$ Some pharmacists have established walking groups which encompass physical and social health benefits. ${ }^{31}$ Such an intervention, a hallmark of community health programs, represents a more community/ environmental strategy. Rather than just offering advice to exercise, pharmacists are facilitating and also providing a supportive environment in which to pursue this activity.

Another area requiring attention is community perceptions and their use of community pharmacy services. Many rural residents only use the dispensing services and do not use the health information services that a pharmacy could provide. ${ }^{45}$ This lack of use suggests a need for marketing the health promotion knowledge and skills of communitypharmacies. The Pharmacy Guild of Australia's nationwide campaign on safe alcohol consumption found that, with appropriate marketing strategies, consumers and pharmacists were more inclined to discuss issues relevant to drug and alcohol interactions. ${ }^{12}$ Thus, marketing, in addition to paid advertising and in-store displays, could be extended to other health behaviours.

\section{CONCLUSION}

Community pharmacy represents a valuable health promotion setting and there is growing research to recommend health promotion pharmacy practice. Given the large proportion of the population frequenting pharmacies even an opportunistic style health promotion approach will have a significant reach At this stage the research base for community pharmacy involvement in targeting healthy behaviours is limited. Furthering this research and program agenda needs to address how community pharmacy fits within a health promotion framework, and the key barriers of remuneration, training and community expectations. Addressing barriers could place community pharmacy as a valuable setting through which to conduct healthy promotion behaviour change campaigns and programs.

Competing interests: None declared.

\section{References}

1. Anderson C. Health promotion in community pharmacy: the UK situation Patient Educ Couns 2000; 39: 285-91.

2. Krass I, Hourihan F, Chen T. Health promotion and screening fo cardiovascular risk factors in NSW: a community pharmacy model. Health Promot J Aust 2003; 14: 101-7.

3. Mayer JA, Eckhardt L, Stepanski BM, Sallis JF, Elder JP, Slymen DJ, et al. Promoting skin cancer prevention counseling by pharmacists. Am J Public Health 1998; 88: 1096-9.

4. Benrimoj SI, Frommer MS. Community pharmacy in Australia. Aust Health Rev 2004; 28: 238-46.

5. Blenkinsopp A, Panton R, Anderson C. Health promotion for pharmacists 2nd ed. Oxford: Oxford University Press; 2000.

6. McGlynn S, Reid F, McAnaw J, Chinwong S, Hudson S. Pharmaceutical care: coronary heart disease. Pharm J 2000; 265: 194-205.

7. Australian Institute of Health and Welfare. Australia's health 2006. Canberra: AIHW; 2006.

8. Department of Health and Ageing. Smoking, nutrition, alcohol and physica activity framework for general practice. Canberra: The Department; 2001. 9. Prochaska JO, DiClemente CC. Stages and processes of self-change of smoking: toward an integrative model of change. J Consult Clin Psychol 1983; 51: 390-5. 10. Maguire TA, McElnay JC, Drummond A. A randomized controlled trial of a smoking cessation intervention based in community pharmacies. Addiction 2001; 96: 325-31.
11. Sinclair HK, Bond CM, Lennox AS, Silcock J, Winfield AJ, Donnan PT. Training pharmacists and pharmacy assistants in the stage-of-change model of smoking cessation: a randomised controlled trial in Scotland. Tob Control 1998; 7: 253-61.

12. May KW. Evaluation of alcohol awareness campaign. Pharm Rev 2004; 28 : 48-9.

13. Berbatis CG. Weight management and the challenges to Australian pharmacy. Aust Pharm 2005; 24: 196-201.

14. Ahrens RA, Hower M, Best AM. Effects of weight reduction interventions by community pharmacists. J Am Pharm Assoc 2003; 43: 583-9.

15. Paluck EC, Stratton TP, Godwin GO. Community pharmacists' participation in health education and disease prevention activities. Can J Public Health 1994; 85: 389-92.

16. O'Loughlin J, Masson P, Dery V, Fagnan D. The role of community pharmacists in health education and disease prevention: a survey of their interests and needs in relation to cardiovascular disease. Prev Med 1999; 28: 324-31.

17. Ruston A. Achieving re-professionalisation: factors that influence the adoption of an 'extended role' by community pharmacists. A national survey. J Soc Adm Pharm 2001; 18: 103-10.

18. Teh R, Chen T, Krass I. Consumer perspectives of pharmacist delivered health information and screening services. Int J Pharm Prac 2001; 9: 261-7.

19. Humphreys JS, Rolley F, Weinand HC. Evaluating the importance of information sources for preventive health care in rural Australia. Aust J Public Health 1993; 17: 149-57.

20. Ghalamkari HH, Rees JE, Saltrese-Taylor A. Evaluation of a pilot health promotion project in pharmacies: (3) client's further opinions and actions taken after receiving health promotion advice. Pharm J 1997; 258: 909-13. 21. Hudmon KS, Hemberger KK, Corelli RL, Kroon LA, Prokhorov AV. The pharmacist's role in smoking cessation counselling: perceptions of users of nonprescription nicotine replacement therapy. J Am Pharm Assoc 2003; 43: 573-82. 22. Williams DM, Newsom JF, Brock TP. An evaluation of smoking cessationrelated activities by pharmacists. J Am Pharm Assoc 2000; 40: 366-70.

23. Moodie R. Introduction: getting your hands on. In: Moodie R, Hulme A, editors. Hands-on health promotion. Melbourne: IP Communications; 2004. 24. Howat P, Maycock B, Cross D, Collins J, Jackson L, Burns S, et al. Towards a more unified definition of health promotion. Health Prom J Aust 2003; 14: 82-5. 25. Howat $P$, Sleet D, Elder R, Maycock B. Preventing alcohol-related traffic injury: a health promotion approach. Traffic Inj Prev 2004; 5: 208-19.

26. Wass A. Promoting health: the primary health care approach. Sydney: Harcout Brace \& Company; 1994

27. Marmot M, Wilkinson RG, editors. Social determinants of health. Oxford: Oxford University Press; 1999

28. World Health Organization. Ottawa charter for health promotion. Geneva: WHO. Available from <www.who/int/hpr/background/ottawacharter.htm>. Accessed 10 May 2006

29. World Health Organization. Jakarta declaration for leading health promotion into the 21 st century. Geneva: WHO. Available from <www.who/int/hpr/ background/jakarta/jakartadeclaration.htm>. Accessed 10 May 2006.

30. Emmerton L. Shaping up in later life. Aust Pharm 2002; 21: 746-8.

31. Gowan J, Roller L. Women's health: exercise and home medication reviews. Aust J Pharm 2003; 84: 144-7.

32. Miller M, Wood L. Smoking cessation interventions: review of evidence and implications for best practice in health care settings. Canberra: Commonwealth Department of Health and Ageing; 2001.

33. Jackson JK, Sweidan M, Spinks JM, Snell B, Duncan GJ. Public healthrecognising the role of Australian pharmacists. J Pharm Pract Res 2004; 34: 290-2. 34. Hawe P. Evaluation. In: Moodie R, Hulme A, editors. Hands-on health promotion. Melbourne: IP Communications; 2004. p. 16-28.

35. Ghalamkari HH, Rees JE, Saltrese-Taylor A, Ramsden M. Evaluation of a pilot health promotion project in pharmacies: (1) quantifying the pharmacist's health promotion role. Pharm J 1997; 258: 138-43.

36. Hourihan F, Krass I, Chen T. Rural community pharmacy: a feasible site for a health promotion and screening service for cardiovascular risk factors. Aust J Rural Health 2003; 11: 28-35.

37. Sinclair HK, Bond CM, Stead LF. Community pharmacy personnel interventions for smoking cessation. Cochrane Database Syst Rev; 2004.

38. Martin K. Breathing life into quit rates. Aust J Pharm 2005; 86: 954-6. 39. Sunderland VB, Burrows SD, Joyce AW, Howat P, McManus A, Maycock B. Supporting the health promotion role of a pharmacist in a small town setting - a preliminary project design city. Bentley: Curtin University; 2006. 40. Australian Health Ministers' Conference. National rural health strategy. Canberra: Commonwealth of Australia; 1994.

41. Gangeness DE. Pharmaceutical care for rural patients: ominous trends. J Am Pharm Assoc 1997; 37: 84.

42. Humphreys JS, Hegney D, Lipscombe J, Gregory G, Chater B. Whither rural health? Reviewing a decade of progress in rural health. Aust J Rural Health 2002; 10: 2-14

43. Lavelle P. Country life: a health hazard? Health Matters. Available from $<$ www.abc.net.au/health/regions/features/countrylife/default.htm $>$. Accessed 9 September 2004

44. Watt IS, Franks AJ, Sheldon TA. Health and health care of rural populations in the UK: is it better or worse? J Epidemiol Community Health 1994; 48: 16-21. 45. Sunderland B, Burrows S, Joyce A, McManus A, Maycock B. Rural pharmacy not delivering on its health promotion potential. Aust J Rural Health 2006; 14: 116-19.

Submitted: 27 July 2006

Accepted after external review: 19 November 2006 